\title{
Enhanced Impact-Resistance of Aeronautical Quasi- Isotropic Composite Plates Through Diffused Water Molecules in Epoxy
}

Furqan Ahmad ( $\square$ furqan640@gmail.com )

Dhofar University

\section{Fethi Abbassi}

American University of the Middle East

Mazhar UI-Islam

Dhofar University

Frédéric JACQUEMIN

University of Nantes

Jung-Wuk Hong

Korea Advanced Institute of Science and Technology

\section{Research Article}

Keywords: Hygroscopic effect, Impact-resistance, Moisture content, Carbon fiber, Low-velocity impact

Posted Date: December 1st, 2020

DOI: https://doi.org/10.21203/rs.3.rs-114297/v1

License: (9) This work is licensed under a Creative Commons Attribution 4.0 International License. Read Full License

Version of Record: A version of this preprint was published at Scientific Reports on January 19th, 2021.

See the published version at https://doi.org/10.1038/s41598-021-81443-w. 


\section{Enhanced Impact-Resistance of Aeronautical Quasi-Isotropic Composite Plates Through}

\section{Diffused Water Molecules in Epoxy}

Furqan Ahmad $^{\text {a, }}$, Fethi Abbassi ${ }^{\text {b }}$, Mazhar Ul-Islam ${ }^{\mathrm{c}}$, Frédéric JACQUEMIN ${ }^{\text {d }}$, Jung-Wuk Hong $^{\mathrm{e}}$

${ }^{a}$ Department of Mechanical and Mechatronics Engineering, Dhofar University, Salalah, Oman

${ }^{\mathrm{b}}$ College of Engineering and Technology, American University of the Middle East, Kuwait

${ }^{\mathrm{c}}$ Department of Chemical Engineering, Dhofar University, Salalah, Oman

${ }^{\mathrm{d}}$ Research Institute in Civil and Mechanical Engineering, University of Nantes, France

${ }^{\mathrm{e}}$ Department of Civil and Environmental Engineering, Korean Advanced Institute of Science and Technology (KAIST), Daejeon, Korea

A Research Paper

Submitted to

'Scientific Reports'

2020

* Corresponding Author: Furqan Ahmad

Tel.: +968-2323-7320

E-mail: fahmad@du.edu.om ; furqan640@gmail.com 


\section{Abstract}

In order to elucidate the hygroscopic effects on impact-resistance of carbon fiber/epoxy quasi-isotropic composite plates, low-velocity impact tests are conducted on dry and hygroscopically conditioned plates, respectively, under identical configurations. For the impact tests, plates were immersed in the hot water at $80{ }^{\circ} \mathrm{C}$ to absorb a different amount of moisture content (MC). Experimental results reveal that the presence of the MC plays a pivotal role by improving the impact-resistance of composite plates. Plates with higher percentage of MC could behave elastically to a larger strain, yielding larger deflection under impact loading. From SEM fractographies, it is observed that small disbanding grows at the interface of epoxy and carbon fiber due to absorbed MC. After absorbing MC, most of impact enegy is dissipated in hygroscopic conditioned composite plates throught elastic deformation and overall less damage is induced in wet composite plates compare to the dry plate. We can postulate that the presence of MC increases the elastic limit as well as ductility of the epoxy by promoting chain segmental mobility of the polymer molecules, which eventually leads to the enhancement of the impactresistance of wet quasi-isotropic composite plates in comparison with the dry plate.

Keywords: Hygroscopic effect; Impact-resistance; Moisture content; Carbon fiber; Low-velocity impact. 


\section{Introduction}

With higher stiffness to weight ratio as well as the improved strength, compared to the conventional structural materials, the composite materials especially carbon fiber composites have been gaining widespread use in many manufacturing industrial areas and are extensively used in the aerospace industry for aircrafts structural components such as wing flaps, engine cowlings, and vertical tail fin stabilizers. More than 37 years ago, the Boeing Commercial Airplanes used carbon fiber composite to manufacture the spoilers of the Boeing 737, a short-tomedium range twinjet narrow-body airline. Composite materials that have less maintenance cost and lighter in weight are replacing the alloy structure in the airplane industry. Boeing Commercial Airplanes company is using almost 50\% composite material by weight for the manufacturing of Boeing 787 Dreamliner airplane. ${ }^{1,2}$

During the service life, composites such as aircraft outer bodies are exposed to different hygro-thermal conditions including changes in humidity and temperature. It has been reported that these different environmental conditions might cause degradation of mechanical properties by weakening the interfacial bonding between fiber and matrix and also cause some changes in the chemical properties of composite materials. ${ }^{3,4}$ These hygro-thermal effects make this study crucial. In literature, only a few published research articles on the effects of hygroscopic conditions up to fully saturated condition on impact-resistance of quasi-isotropic composite materials are available. Zhong and Joshi ${ }^{5}$ performed impact tests on the normal and staggered lay-up composite structures which were exposed to hygroscopic condition and observed that 
impact resistance of wet composite structures increased. Zhou and Zhong ${ }^{6}$ checked the hygrothermal effects on the properties of glass-vinyl ester composite which were exposed to freezethaw cycling. Then they performed the compression tests on the composites and observed degradation of compression properties. Mokhtar et al. $^{7}$ studied the influence of aging on the impact damage of three different lay-ups of carbon fiber/epoxy composite plates and found that morphology of the impact damage in composite plates was significantly influenced by the aging process. Aoki et al. ${ }^{8}$ investigate the combined effects of thermal environmental conditions and moisture absorption on the compression of carbon fiber composite plates. They found that due to the presence of moisture the compression of the composite plate decreased slightly at $149{ }^{\circ} \mathrm{C}$ and significantly at $177{ }^{\circ} \mathrm{C}$. Lu et al. ${ }^{9}$ investigate the effects of thermal conditions on the impact resistance of a unidirectional carbon fiber composite plate. The behavior of dry and hygroscopically conditioned composite materials under impact loading has major concern because impact load can cause different damages in composite materials such as matrix cracking, delamination between two adjusted layers, fiber and matrix interfacial disbanding, and breakage of fiber. ${ }^{10,11}$ During manufacturing as well as maintenance and repair, composite structures might experience the low-velocity impact load by dropping any tool, which causes damage in the structures and ultimately leads to the failure of structures. ${ }^{12,13}$

In the literature, no article is available on the effects of hygroscopic conditions (up to fully saturated condition) on the impact-resistance of quasi-isotropic composite materials due to its complex structure. Therefore, in this study, we investigate the effects of hygroscopic conditions 
up to fully saturated condition on the impact-resistance of carbon fiber/epoxy quasi-isotropic composite plate $\left[0^{\circ} / 45^{\circ} / 90^{\circ} /-45^{\circ}\right]_{\mathrm{s}}$ under low-velocity impact loading. The main objectives of this study are to discern the relationship between the hygroscopic condition and impact-resistance of quasi-isotropic composite plate and to understand the mechanism by which MC changes the impact properties of the composite material. To achieve the main objective, low-velocity impact tests were performed using an impact testing machine on five different MC conditions: dry plate $0 \%\left(Q_{1}\right), 0.75 \%\left(Q_{2}\right), 1.0 \%\left(Q_{3}\right), 1.1 \%\left(Q_{4}\right)$, and fully saturated plate $1.36 \%\left(Q_{5}\right)$. Composite plates were immersed in the distilled water to absorb the MC, and the temperature of the water was maintained at $80{ }^{\circ} \mathrm{C}$ to accelerate the absorption process. Fully saturated condition of the quasi-isotropic carbon fiber composite plate cannot be easily achieved because a long period of time (almost one and half year) is required, and consequently, data about the impact-resistance of fully saturated quasi-isotropic composite plates are rare in literature. Plates with a higher percentage of MC could behave elastically up to the higher level of strain and show larger deflection under impact loading. Wet quasi-isotropic composite plates show better impactresistance in comparison with the dry plate due to presence of absorbed $\mathrm{MC}$, which improves the ductility of the epoxy by promoting chain segmental mobility of the polymer molecules.

\section{Results}

\section{Moisture absorption behavior and its effects}

It is well known that the carbon fibers absorb a neglectable amount of water compared to the matrix (epoxy) in a humid environment. When the carbon fiber composite plate immersed in 
the water, the water molecules do not diffuse at the surface of the plate and inside the plate because the carbon fibers change the diffusion path of the water molecules and hindering straight diffusion. Compared to any other stacking sequence, the quasi-isotropic plate shows maximum resistance to water molecules to diffuse inside the plate. ${ }^{4}$

For each MC condition, weights of three dry specimens were measured, and then those specimens were immersed in the hot water at $80{ }^{\circ} \mathrm{C}$. All plates were dipped completely into the water, and their average dry and wet weights for different MC conditions are listed in Table 1. From the moisture absorption curve in Figure 1, it is observed that the dry plate absorbs water quickly and the curve raises linearly up until it absorbed almost $65 \%$ of its final saturated MC level. After that, the water absorption rate becomes very slow and the curve converges to the point of saturation. The composite plate absorbs the water molecules of $0.75 \%$ of its weight in the time period of 729 hours and then took a long time of 1640.25 hours to reach MC level of $1.0 \%$. The $1.1 \% \mathrm{MC}$ level, which is the fourth condition in this study, was achieved in the time period of $2,956.1$ hours. To achieve a fully saturated level which is $1.36 \%$, we need the immersion time of $12,613.54$ hours. To analyze the hygroscopic effects on the strength of the interfacial bond between the reinforced carbon fibers and epoxy matrix SEM, fractographies were performed for the fully dry and fully saturated plates as shown in Figure 2. For the completely dry composite plate, a tight interfacial bonding between the carbon fiber and epoxy is seen clearly in Figure 2 (a). When composite plates immersed in the hot water, the carbon fibers do not absorb the water, and the moisture expansion coefficient is almost zero while the epoxy 
matrix has a high moisture expansion coefficient and absorbs almost all of the water molecules.

Due to absorbing water molecules, the epoxy matrix swelled up and caused interfacial debonding with the carbon fibers as shown in Figure 2 (b).

\section{Low-velocity impact behavior}

To investigate the hygroscopic effect on the quasi-isotropic composite plates, all experimental low-velocity impact tests were performed using identical impact energy. To understand completely the hygroscopic effect, a range of experimental tests from fully dry to fully saturated conditions were performed. Firstly, impact tests were performed for the fully dry composite plate $\left(Q_{1}\right)$ and its experimental results were set as a reference. Later, four more impact tests were performed for different absorbed MC conditions (percentage by weight of composite plates) such as $0.75 \%\left(Q_{2}\right), 1.0 \%\left(Q_{3}\right), 1.1 \%\left(Q_{4}\right)$, and fully saturated $1.36 \%\left(Q_{5}\right)$. Fully saturated condition of the quasi-isotropic carbon fiber composite plate cannot be achieved easily as a long period of time (almost one and half year) is required.

When the hemispherical shaped impactor contacts on the surfaces of the composite plates, the responses of those composite plates were obtained in form of voltage versus time graphs using a load cell, and later these data were converted to force versus time graphs. Complete depiction of the contact between hemispherical shape impactor and composite plates can be studied from the force versus time graph which gives the details of incipient damage, layer-bylayer damage growth, and overall changes in the impact-resistance of the composite plates. Force versus time graphs for all the quasi-isotropic composite plates is shown in Figure 3. During the 
experimental tests, as the impactor hit the top layer of $0^{\circ}$ of the composite plates, the impact damages in form of matrix cracking at a micro-level and delamination between the adjacent layers started and these damages can be observed as an oscillation at the beginning of the force curves. These oscillations in the force curves are referred to as Hertzian failure of the composite materials. All the curves moved toward their peak force values with the almost same slope, which indicates the out-of-plane stiffness of the quasi-isotropic composite plates does not affect. Initially, the majority of the impact load was carried by the carbon fibers which were not affected by the absorbed MC. All the curves reached their peak force values in a linear manner without any oscillations in a short period of time. After the peak force point, a sharp drop was observed which is the indication of rapid extension of damages. Through the thickness of the plates, damages occurred in the form of matrix cracking and fiber breakage which appears as large scale oscillations in the force curves. For the first four cases $\left(Q_{1}\right.$ to $\left.Q_{4}\right)$, after the large scale oscillations, again a sharp drop happened which is the indication that all carbon fiber dominated layers of composite plates are broken and impactor is perforated through the plates. Small scale oscillations happened after the perforation due to the friction between the perforated plates and impactor surface during the downward movement of the impactor. For the fully saturated composite plate $\left(Q_{5}\right)$, after the large scale oscillations, a smooth drop of the curve was observed which is the indication that the impactor is rebounding back and no damage occurred in this rebound portion. Impact event characteristics changed because of the absorbed MC from the supercritical impact event for the $Q_{1}$ composite plate to the critical impact event for the $Q_{5}$ 
composite plate. ${ }^{14,15} Q_{5}$ composite plate got the highest peak force value of $6.054 \mathrm{kN}$ and $Q_{1}$ composite plate showed the lowest peak force value of $4.651 \mathrm{kN}$ which means due to absorbed MC the impact-resistance of the quasi-isotropic composite plates increased. The time corresponding to the peak force value also increased with the increase of the percentage of the absorbed MC, implying that the first significant damage of quasi-isotropic or occurrence of incipient damage is delayed by $0.275 \mathrm{msec}$ for $Q_{5}$ composite plate from the $Q_{1}$ composite plate as shown in Figure 3. The peak force values and their corresponding times for all specimens are shown in Table 2.

Kinematics formulas defined in following Equations 1 and 2 are used to extract the impactor velocity and displacement data from the impact force versus time graphs for the better understanding of the impact behavior of the dry and moisture absorbed quasi-isotropic composite plates under low-velocity impact loading.

$$
\begin{gathered}
v_{t}=v_{i}-\frac{1}{m_{i}} \int_{0}^{t} F_{i} d t \\
d_{t}=d_{i}+\int_{0}^{t} v_{t} d t
\end{gathered}
$$

where $v_{\mathrm{t}}$ and $d_{\mathrm{t}}$ is the impactor velocity and displacement at time $t, v_{\mathrm{i}}$ and $d_{\mathrm{i}}$ is the initial velocity and displacement of the impactor just before contact with the top surface of the composite plate, $F_{\mathrm{i}}$ is the recorded force of the impact and $m_{\mathrm{i}}$ is the impactor load. The time-velocity curves for all the quasi-isotropic composite plates are shown in Figure 4. For the first four cases $\left(Q_{1}\right.$ to $\left.Q_{4}\right)$, the impactor velocity curves dropped quickly from their initial value of $3.71 \mathrm{~m} / \mathrm{sec}$ to the time at the second sharp drop in the time-force curves occurred which is corresponding to the failure of the 
composite layers and impactor is perforated through all layers. The time corresponding to this point is called transition time (showing with dotted black arrow) and after this point, the drop in the curves is small and linear which is the indications that the length of the impactor is passing slowly through the thickness of the composite plates. For the $Q_{5}$ composite plate, the timevelocity curve dropped quickly from the initial velocity level and become zero at the transition time (showing with dotted red arrow) and after this point, the velocity of impactor become negative which mean the impactor started to rebound. The rebound of the impactor cannot be observed in the time-force curve so that's why it is important to draw the impactor velocity graph for a better understanding of the impact behavior of the quasi-isotropic composite plates. With the increase in the percentage of $\mathrm{MC}$, the transition time of composite plates increased. Timeimpactor displacement curves for all five MC conditions are shown in Figure 5. During the impact tests, the impactor kept moving without any barrier on it and displacement curves for the first four $\left(Q_{1}\right.$ to $\left.Q_{4}\right)$ cases increased. $Q_{1}$ composite plate shows less resistance to the impactor and got the maximum displacement value of $18.68 \mathrm{~mm}$ at a time of $10 \mathrm{msec}$ and at the same time $Q_{4}$ composite plate shows less displacement level of $13.29 \mathrm{~mm}$. Impactor does not perforate through the $Q_{5}$ composite plate and when at the point of impact maximum deflection of the plate occurred, the impactor achieved its maximum displacement of $9.47 \mathrm{~mm}$ and after the transition time impactor started to rebound back to zero displacement position (original level) where it will be completely detached from the top layer of $0^{\circ}$. The displacement versus force curves of all the five MC conditioned specimens are shown in Figure 6. This rebound back of the hemispherical 
head impactor can also be observed in Figure 6 where displacement versus force curve started to fold with decreasing displacement of the impactor. As impactor perforated through the first four quasi-isotropic composite plates $\left(Q_{1}\right.$ to $\left.Q_{4}\right)$, there is no fold of displacement versus force curves observed for these specimens. Displacement of the impactor decrease with the increase of MC and impactor rebound back for $Q_{5}$ specimens indicated that the impact-resistance of quasiisotropic composite plates improved under hygroscopic effect.

To analysis the hygroscopic effect on the impact-resistance of the quasi-isotropic composite plates, impact tests were performed under the same level of impact energy of $23.67 \mathrm{~J}$. Energy versus time graphs for all the quasi-isotropic composite plates are shown in Figure 7. During the impact tests, energy absorbed by the quasi-isotropic composite plates from the energy applied by the impactor was calculated as

$$
\begin{gathered}
E_{i}=\frac{m_{i}}{2} v_{i}{ }^{2} \\
E_{a}=\frac{m_{i}}{2} v_{i}{ }^{2}-\frac{m_{i}}{2} v_{t}{ }^{2}
\end{gathered}
$$

where $E_{\mathrm{i}}$ is the initial or applied energy and $E_{a}$ is the absorbed energy. In Figure 7, energy curves can be categorized into two cases: impactor perforated through the plates (for first four cases $Q_{1}$ to $Q_{4}$ ) and impactor penetrated into the plate (for $Q_{5}$ composite plate) and rebound back. Initially, the rate to absorb the impact energy was very low for all the composite plates which attributed as the initiation of damage in form of dent on the top surface and crack along the thickness direction at the point of impact. After that between the time period of 1 to $2 \mathrm{msec}$, the composite plates absorbed the impact energy during the deflection of the composite plates and the slopes of 
all energy curves were increased quickly and internal damages produced in composite plates. Energy curves for the first four cases $\left(Q_{1}\right.$ to $\left.Q_{4}\right)$, rise with a large slope progressively until the maximum deflection of the composite plates reached and internal damages started in the plates. When the impactor perforated through these composite plates, maximum energy was absorbed by the plates after that the energy curves appeared to further increase because the later surface of the impactor still has contact with the circular edges of the perforated plates. For the $Q_{5}$ composite plate, after reaching the peak point the energy curve starts decreasing progressively which is an indication that impactor has started the rebound. It is reasonable to state that when the impactor and plate detached complete, any further absorption of the energy did not occur.

Force versus time curves for all the composite plates can be divided into two distinct regions: a region before the peak force can be referred to as fracture initiation region and region after the peak force point is referred to as the fracture propagation region. The energy absorbed by the composite plate up to peak force point and required for fracture ignition can be defined as initiation energy $\left(E_{\text {ini }}\right)$. As energy curves categorized in two cases so it is reasonable to compare the initiation energies for all the plates. $E_{\text {ini }}$ values for all the five cases $\left(Q_{1}\right.$ to $\left.Q_{5}\right)$ are listed in Table $2, Q_{5}$ composite plate has the highest initiation energy and the lowest is for the $Q_{1}$ composite plate. With the increase of MC, the value of the initiation energy increased.

To check how much energy was absorbed by the composite plates to reach the peak force point, an absorbed energy ratio $\left(R_{a} \%\right)$ is introduced to compare the ratio of initiation energy over the energy applied by the impactor as 


$$
R_{a}(\%)=\frac{E_{\text {ini }}}{E_{\text {applied }}} \times 100
$$

and those values are listed in Table 2 for all composite plates. As $Q_{5}$ composite plate has the highest peak force point and got the absorbed energy ratio of $50.729 \%$ and lowest ratio $(35.647 \%)$ is for the $Q_{1}$ composite plate.

After the peak force point or initiation energy, energy curves further increased and reached to their maximum point $\left(E_{\max }\right)$ which is corresponding to the perforation of the composite plates $\left(Q_{1}\right.$ to $\left.Q_{4}\right)$ and the maximum deflection of the fully saturated composite plate $\left(Q_{5}\right)$. It is reasonable to assume that energy absorbed by composite plates from initiation to maximum energy points was utilized to produce the major damages such as delamination and energy absorbed between these two points is referred to as residual energy $\left(E_{\mathrm{res}}\right)$, defined in the following Equation 6. The initiation energy, maximum energy and residual energy for composite plates with five different MC conditions are listed in Table 2.

$$
E_{\text {res }}=E_{\text {max }}-E_{\text {ini }}
$$

From Table 2 it is also clear that $Q_{5}$ composite plate has maximum initiation energy $(12.008 \mathrm{~J})$ and utilized more than $51 \%$ of applied energy to reach the peak force point and reaming $49 \%$ was used to produce the damages. $Q_{1}$ composite plate reached more quickly to peak force point by using the $8.438 \mathrm{~J}$ initiation energy and utilized almost $35 \%$ of applied energy to reach this point and the remaining $65 \%$ of applied energy was used to produce the damages.

\section{Impact damage analysis}


Whenever an object falls on the composite structures, a complicated damage mechanism consists of different failure modes are created. Matrix cracking, fiber and matrix breakage, fiber and matrix interfacial debonding, inter-laminar cracking, and delamination are the major damage modes that will occur under impact loading and these modes also interact with each other. ${ }^{16,17}$ Damage in the form of matrix failure initiates in the composite materials when the applied impact energy surpassed the threshold level. Compared to the matrix, more impact energy required to fail the fibers in the composite materials. It is reasonable to say that strength and impact impact-resistance of the composite materials mainly depend more on matrix strength than the fiber strength. For all five cases $\left(Q_{1}\right.$ to $\left.Q_{5}\right)$, when impactor dropped on top face of the composite plates, fiber breakage, fiber cracking, and matrix cracking were observed as shown in Figure 8 for $Q_{1}$ composite plate. At the point of impact, fibers were broken and the matrix was failed due to indentation effects which cause local high stresses. The top and bottom faces of the $Q_{1}$ composite plate are shown in Figure 9(i). As the impactor perforated through this plate, circular shape damage was observed on the front face and underneath the impact point between the last two layers delamination was occurred. Impactor did not perforate through the $Q_{5}$ composite plate but create a large dent on the top face as shown in Figure 9(ii). Different damage modes such as matrix and fiber crushing, matrix cracking, and fibers breakage took place underneath of impact point on the top face, and delamination was observed on the back face. From Figure 9 it can be observed that more damages occurred in the $Q_{1}$ composite plate compare to the $Q_{5}$ composite plate means impact-resistance of quasi-isotropic composite plates improved 
with the presence of absorbed MC.

\section{Discussion}

Based on the low-velocity impact test results, it can be concluded that the elastic deformation capacity of the composite plates was improved by absorbing the MC. From the SEM fractography (Figure 2) of fully dry $\left(Q_{1}\right)$ and saturated $\left(Q_{5}\right)$ composite plates, it was observed that absorbed MC had minimal effects on the carbon fibers and had some effect on the interfacial bond between fiber and matrix. Therefore, it can be postulated that absorbed MC affects the matrix resin and improve the elastic deformation capacity of composite plates. ${ }^{5,6}$ Compare to the water molecules, the molecules of the cured epoxy are large in size. That's why water molecules can diffuse into the epoxy resin network easily and reside in the vacancies between the chains of the epoxy molecules and cause an increase in the overall thickness of the composite plate and expansion of its volume. The covalent bond force between the small molecules are normally greater in magnitude (one to two times) compare to the Van der Waals force. Polymers molecules have long structural chains and greater in the number which characterized them huge molar mass structures. The inter-molecular force (Van der Waals force) of the long structural chain of the polymer molecule is comparatively high than the covalent bond force. Figure 10 shows the formation of the crosslinked polymers from reactants (epoxy and amine hardener). During the curing cycle, each amine group of the hardener molecule (Diethylenetriamine (DETA) or Meta Phenylene Diamine (MPDA) hardener) have two active atoms of the hydrogen which react with the epoxy (Diglycidyl Ether of Bisphenol A (DGEBA) 
molecule) molecule and form the long-chain structure of the crosslinked polymers and intermolecular force became stronger than the covalent bond force. ${ }^{5,6}$ This strong inter-molecular force leads to the brittle behavior of the fully dried composite material under the impact loading. The inter-molecular force in the long structure of the polymer molecule is classified into two parts, Van der Waals force, and hydrogen bonding. Van der Waals force is further divided into three parts such as orientation force, induction force, and dispersion forces as shown in Figure 11(a). There are two aspects by which the intermolecular force of polymer molecule can be weakened by the interaction between the epoxy resin and water molecules (Figure 11(b)). Firstly, the Van der Waals force between the polymer molecules is effective up to a certain distance and beyond this distance starts to become weaker. As large-sized water molecules diffused in the long structure of the polymer molecules, the distance between the polymer molecules increased and the Van der Waals force becomes weak. Induction and orientation forces are mainly depending upon the polar groups of the polymer molecules and water molecules are also polar molecules as shown in Figure 11(b). So, the water molecules make coupling with the polymer molecules and weaken the induction and orientation forces. Secondly, the amine and hydroxyl groups of the epoxy resin are ready to make the hydrogen bonding. The diffused water molecules can also create hydrogen bonding with epoxy molecular chains and reduced the number of hydrogen bonding of the epoxy resin. Due to the expansion of the volume of the epoxy resin, some hydrogen bonds may also destroy. Therefore, hydrogen bonding became weak due to the presence of the absorbed MC. It can be concluded that overall inter-molecular attractive forces of 
the long-chain epoxy resin were became weakened due to the presence of the absorbed MCs by hindering the Van der Waals forces and disrupting the hydrogen bonding of the epoxy resin. The behavior of the hygroscopic composite plates changed from brittle to ductile because of promotion in the movement of the various epoxy resin molecules and other molecules against each other.

As shown in Figure 3, time to reach the peak force point is a delay with the increase of MC and the occurrence of the first significant damage or a sharp drop in the time-force curves also delayed. This delay in the first significant damage can also be observed in Figure 6 which shows that damages in $Q_{5}$ composite plate started at the larger displacement of the impactor corresponding to higher strain level compare to $Q_{1}$ composite plate. This delay in the occurrence of the damages shows that the ductility of matrix resin improved due to the presence of MC. The improved ductility would benefit the laminate by hindering the initiation of inter-laminar cracks and matrix cracking but debonding and fiber breakage will not be delayed. Improved ductility of the matrix resin, increased the strain to first significant failure and hygroscopic conditioned quasi-isotropic composite plates preserved their structural integrity up to a large displacement of the impactor. The ductility of matrix resin increase with the increase of the percentage of MC.

\section{Conclusions}

An experimental to investigation the hygroscopic effect on the impact-resistance of symmetric quasi-isotropic CFRP composite plates under low-velocity impact loading was presented in this study. From the current experimental study for different percentages of MC, the 
following conclusive remarks are drawn. Presence of the carbon fiber in quasi-isotropic composite plate cause hindering to the water molecules in straight diffusion by changing the diffusion path. Therefore, it took more than one and a half years to reach a fully saturated point. From the SEM images, it was observed that absorbed MC cause debonding between matrix resin and carbon fiber at their interfacial. From the low-velocity impact results, it was observed that with the increase of MC percentage the time to reach peak force point and peak force values increased. From the impactor velocity and displacement curves it was observed that impactor was perforated through the first four composite plates $\left(Q_{1}\right.$ to $\left.Q_{4}\right)$ and impactor rebound for fully saturated composite plate $\left(Q_{5}\right)$. Initiation energies and absorbed energy ratios increase with the increase of the percentage of $\mathrm{MC}$ and residual energy decreases. A delay in first significant damage was observed due to increase ductility of composite plates and damages in fully saturated $\left(Q_{5}\right)$ composite plate occurred at the larger displacement of the impactor compare to fully dry $\left(Q_{1}\right)$ composite plate. The overall size of damages on the top and bottom faces decreases with an increase of the percentage of MC. More damage was observed for the fully dry composite plate $\left(Q_{1}\right)$ compared to hygroscopic conditioned composite plates $\left(Q_{2}\right.$ to $\left.Q_{5}\right)$. From the current study, it is reasonable to say that the presence of the MC improved the ductility of quasiisotropic composite plates and eventually enhanced the impact-resistance of the quasi-isotropic composite plates under low-velocity impact loading.

\section{Methods}

\section{Composite material and specimens}


Quasi-isotropic composite plates are fabricated from pre-impregnated unidirectional carbon fiber (T800/3900) tape manufactured by the Toray Industry, Inc. This tape consists of intermediate modulus carbon fiber (T800) and $350{ }^{\circ} \mathrm{F}$ cure-type toughened epoxy (3900). The material has a standard $55.5 \%$ fiber volume fraction. From the roll of carbon fiber unidirectional pre-impregnated tape, large pieces of $1000 \mathrm{~mm} \times 1000 \mathrm{~mm}$ were cut at fiber angle of $0^{\circ}$ and $45^{\circ}$. Then, the pieces were laid-up to fabricated the symmetric quasi-isotropic composite plate $\left[0^{\circ} / 45^{\circ} / 90^{\circ} /-45^{\circ}\right]_{\mathrm{s}}$ of eight plies. For the curing purpose, an autoclave with good control on curing parameters such as vacuum, heat-up rate, temperature, and the pressure was used. From the fabricated large panels, square plates of $125 \mathrm{~mm} \times 125 \mathrm{~mm}$ with a nominal thickness of $1.5 \mathrm{~mm}$ were cut. The mechanical properties of a single lamina obtained from the company are listed in Table 3.

\section{Experimental setup}

To observe the water absorption behavior of the quasi-isotropic composite plate, an accelerated immersion water test was performed. A preconditioning procedure was performed by putting the composite plates in the oven at $50{ }^{\circ} \mathrm{C}$ to remove the residual $\mathrm{MC}$ and make them completely dry. Before putting plates to the refrigeration bath circulating machine, the dry weight $\left(W_{\mathrm{d}}\right)$ of each plate was recorded with precision electric weight scale with high-level of accuracy $( \pm 0.0001 \mathrm{~g})$ and later it will be used as a reference for each plate. The tub of the refrigeration bath circulating machine was filled with distilled water and a high temperature of $80{ }^{\circ} \mathrm{C}$ was set to accelerate the water transport process. This temperature is lower than the 
melting point of the quasi-isotropic composite plates and epoxy glass transition temperature $\left(T_{\mathrm{g}}\right)$.

Composite plates were fully immersed in the water and taken out from the water and their wet weight $\left(W_{\mathrm{w}}\right)$ was recorded after a specific interval of three days. Before measuring the wet water, the available water drops were completely removed from the surfaces of the plates to avoid the error in measurements. To avoid discontinuity in the water absorption process and any environmental effect, the weight was recorded in a short period of time. Based on the periodic $W_{\mathrm{w}}$ measurements, the percentage of water absorbed by the composite plates were measured using Equation 7.

$$
M(\%)=\frac{W_{w}-W_{d}}{W_{d}} X 100
$$

According to the ASTM standard ${ }^{18}$, if the aspect ratio (width/thickness) of the composite plate is smaller than 100, the diffusion of the water molecules will be Fickian diffusion. Therefore, the diffusion takes place through the thickness direction of the plate and the edge's effects can be neglected. In the current study, the aspect ratio of the quasi-isotropic composite plate is 83.33 , which is smaller than the 100 . Consequently, Fick's diffusion law ${ }^{19}$ was used to calculate the water diffusion coefficients of the composite plate. The water diffusivity $\left(D_{\mathrm{t}}\right)$ through the plate thickness direction is written as

$$
D_{t}=\pi\left(\frac{t_{c p}}{4 M C_{e q}}\right)^{2}\left(\frac{M C_{2}-M C_{1}}{\sqrt{t_{2}}-\sqrt{t_{1}}}\right)^{2}
$$

where $t_{c p}$ is the composite plate thickness, $M C_{\text {eq }}$ is the equilibrium percentage of the $\mathrm{MC}$, and $M C_{1}$ and $M C_{2}$ are two different MC levels measured after the time intervals of $t_{1}$ and $t_{2}$, 
respectively.

Vertical impact testing machine was used to perform the low-velocity impact tests on dry and hygroscopic conditioned quasi-isotropic composite plates. Schematic diagram of the complete low-velocity impact testing set up is shown in Figure 12. The total mass of impactor $\left(m_{\mathrm{i}}\right)$ including all add-on weights and load cell was $3.44 \mathrm{~kg}$ and $0.7 \mathrm{~m}$ height of impactor $\left(h_{\mathrm{i}}\right)$ was selected corresponding to initial impact velocity $\left(v_{\mathrm{i}}\right)$ of $3.71 \mathrm{~m} / \mathrm{sec}$ and provide the impact energy of 23.67 J. To analyze the hygroscopic effect, all the composite plates were tested under constant boundary conditions. Composite plates were put on the steel plate support that has a circular cut of $75 \mathrm{~mm}$ diameter at the center to allow perforation of impactor through the thickness of plates without any interference. To prevent the in and out of plane movement of the composite plate, the plates were clamped at four corners by the rubber-tipped clamps those applying the light clamping pressure. All this arrangement simulates the simply-supported boundary condition. For each hygroscopic condition, three impact tests were performed to avoid the experimental error and after impact test, composite plates were removed from the fixture with care for the postimpact damage analyses.

\section{References}

1. Liu, YN., Yuan, C., Liu, C. et al. Study on the resin infusion process based on automated fiber placement fabricated dry fiber preform. Scientific Reports 9, 7440 (2019).

2. Sandeep, SP., Tarun, K., Yogesh, MD. Application of polymer composites in civil construction: A general review. Composite Structures 84(2), 114-124 (2008). 
3. Furqan, A., Fethi, A., Hong, JW., Chang, SH., Park, MK. Hygroscopic effects on the impactresistance behavior of a specially-orthotropic CFRP composite plates. Composite Structures 176, 1073-1080 (2017).

4. Furqna, A., Hong, JW., Choi, HS., Park MK. Hygro effects on the low-velocity impact behavior of unidirectional CFRP composite plates for aircraft applications. Composite Structures 135, 276-285 (2016).

5. Zhong, Y., Joshi, SC. Impact resistance of hygrothermally conditioned composite laminates with different lay-ups. Journal of Composite Materials 49(7), 829-841 (2015).

6. Zhou, J., Zhong, Y. Effect of hygrothermal cycling on properties of glass-vinyl ester composite. Journal of Reinforced Plastics and Composites 23(5), 83-90 (2004).

7. Mokhtar, H., Sicot, O., Rousseau, J., Yulfian, A., Aivazzadeh, S. The influence of ageing on the impact damage of carbon epoxy composites. Procedia Engineering 10, 2615-20 (2011).

8. Aoki, Y., Yamada, K., Ishikawa, T. Effect of hygrothermal condition on compression after impact strength of CFRP laminates. Composite Science and Technology 68(6), 1376-83 (2008).

9. Lu XJ., Qi, Z. Effect of water absorption on the impact properties of carbon fiber/epoxy composites. Chinese Journal of Aeronautics 19(S1), 14-8 (2006).

10. Zhu, S., Chai GB. Damage and failure mode maps of composite sandwich panel subjected to quasi-static indentation and low velocity impact. Composite Structures 101, 204-214 (2013).

11. Furqna, A., Hong, JW., Choi, HS., Park MK. The effects of stacking sequence on the 
penetration-resistant behaviors of T800 carbon fiber composite plates under low-velocity impact loading. Carbon Letters 6(2), 107-115 (2015).

12. Boria, S., Scattina, A., Belingardi, G. Impact behavior of a fully thermoplastic composite. Composite Structures 167, 63-75 (2017).

13. Yang, K., Wu, S., Guan, J., Shao, Z., Ritchie, RO. Enhancing the Mechanical Toughness of Epoxy-Resin Composites Using Natural Silk Reinforcements. Scientific Reports 7, 11939 (2017).

14. Feraboli, P., Kedward, KT. Enhanced evaluation of the low-velocity impact response of composite plates. AIAA Journal 42, 2143-2152 (2004).

15. Feraboli, P. Some recommendations for characterization of composite panels by means of drop tower impact testing. Journal of Aircraft 43, 1710-1718 (2006).

16. Furqan, A., Fethi, A., Park, MK., Hong, JW. Numerical investigation to evaluate effect of fiber orientation on impact-resistance of an aircraft composite material. Mechanics of Advanced Materials and Structures 26, 1613-1621 (2019).

17. Furqan, A., Fethi, A., Park, MK., Jung, JW., Hong, JW. Finite element analysis for the evaluation of the low-velocity impact response of a composite plate. Advanced Composite Materials 28, 271-285 (2019).

18. Standard test method for moisture absorption properties and equilibrium conditioning of polymer matrix composite materials (ASTM D5229/D5229M - 12.), ASTM: West Conshohocken, (2012). 
19. Shen, CH., Springer GS. Moisture absorption and desorption of composite materials. Journal of Composite Materials 10, 2-20 (1976). 
Figures

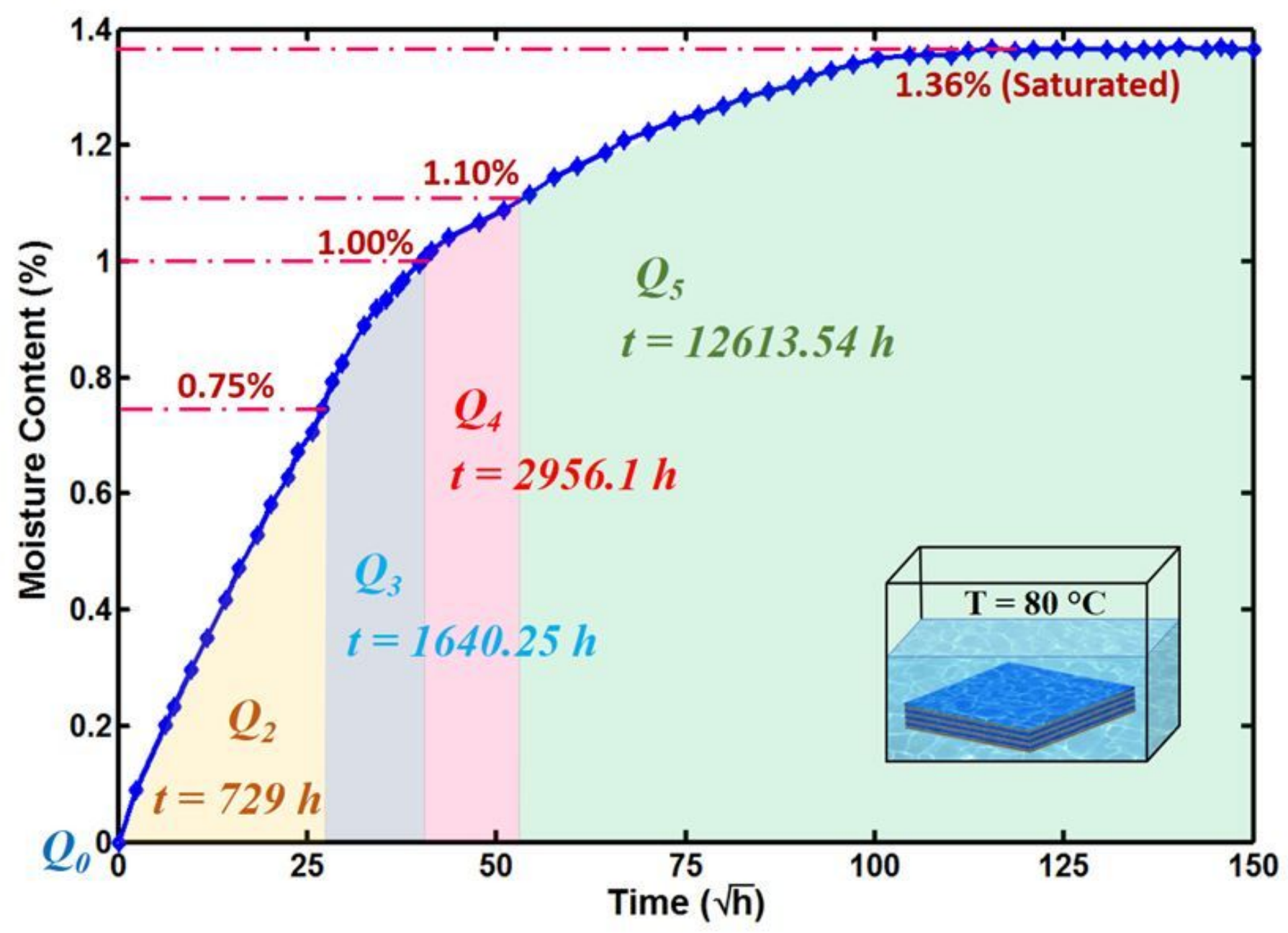

Figure 1

Water absorption behavior of quasi-isotropic composite plate at $80^{\circ} \mathrm{C}$. 


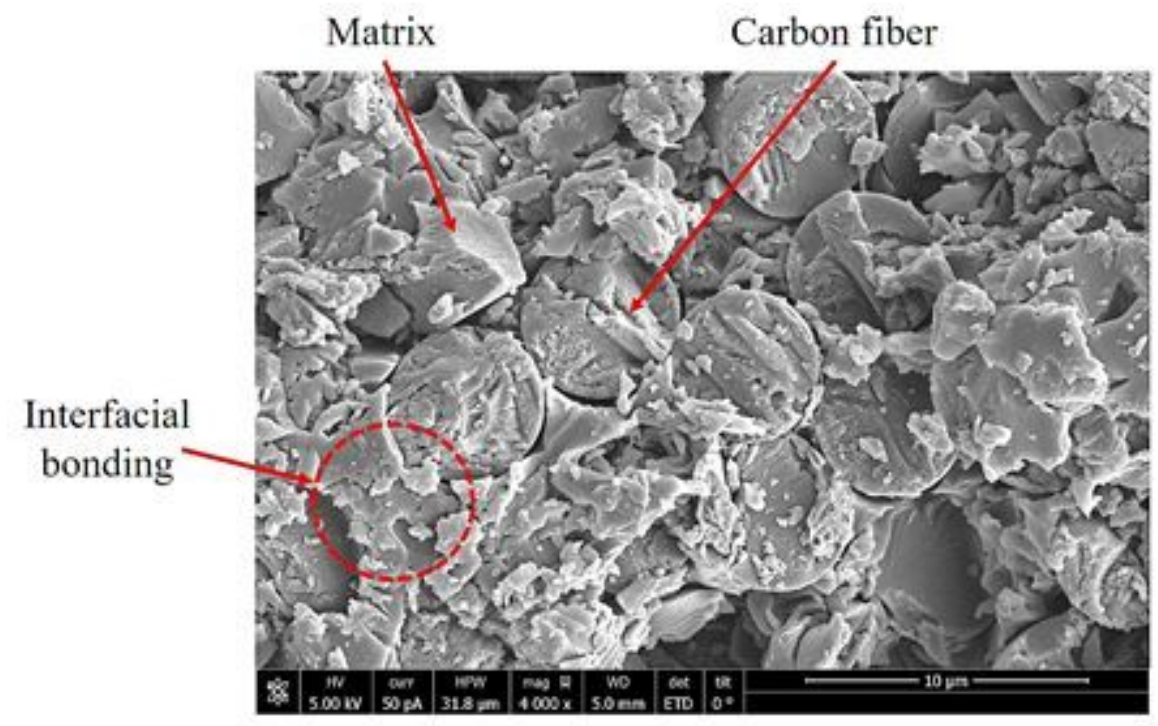

(a) Fractography of fully dry quasi-isotropic composite plate $\left(Q_{1}\right)$.

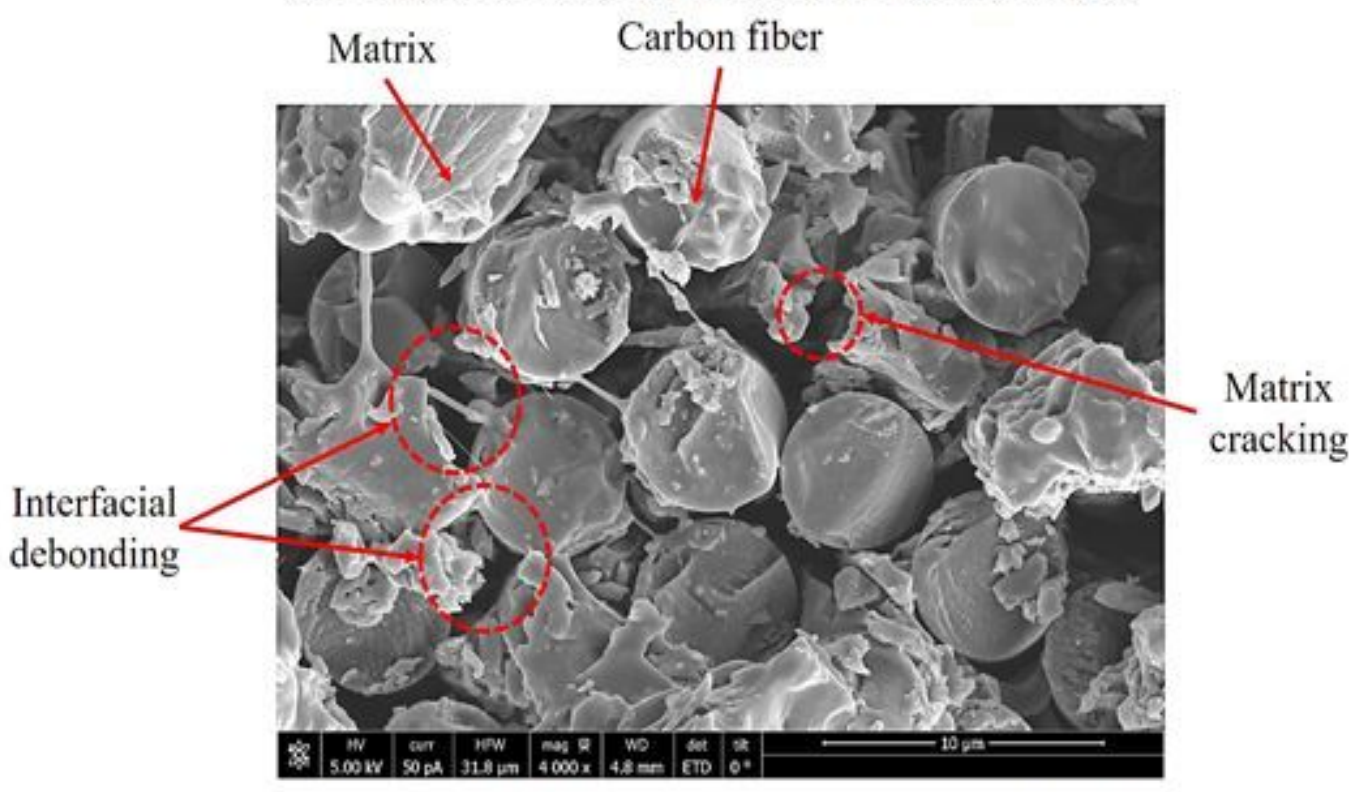

(b) Fractography of fully saturated quasi-isotropic composite plate $\left(Q_{s}\right)$.

\section{Figure 2}

SEM fractographies for (a) fully dry and (b) fully saturation quasi-isotropic composite plates. 


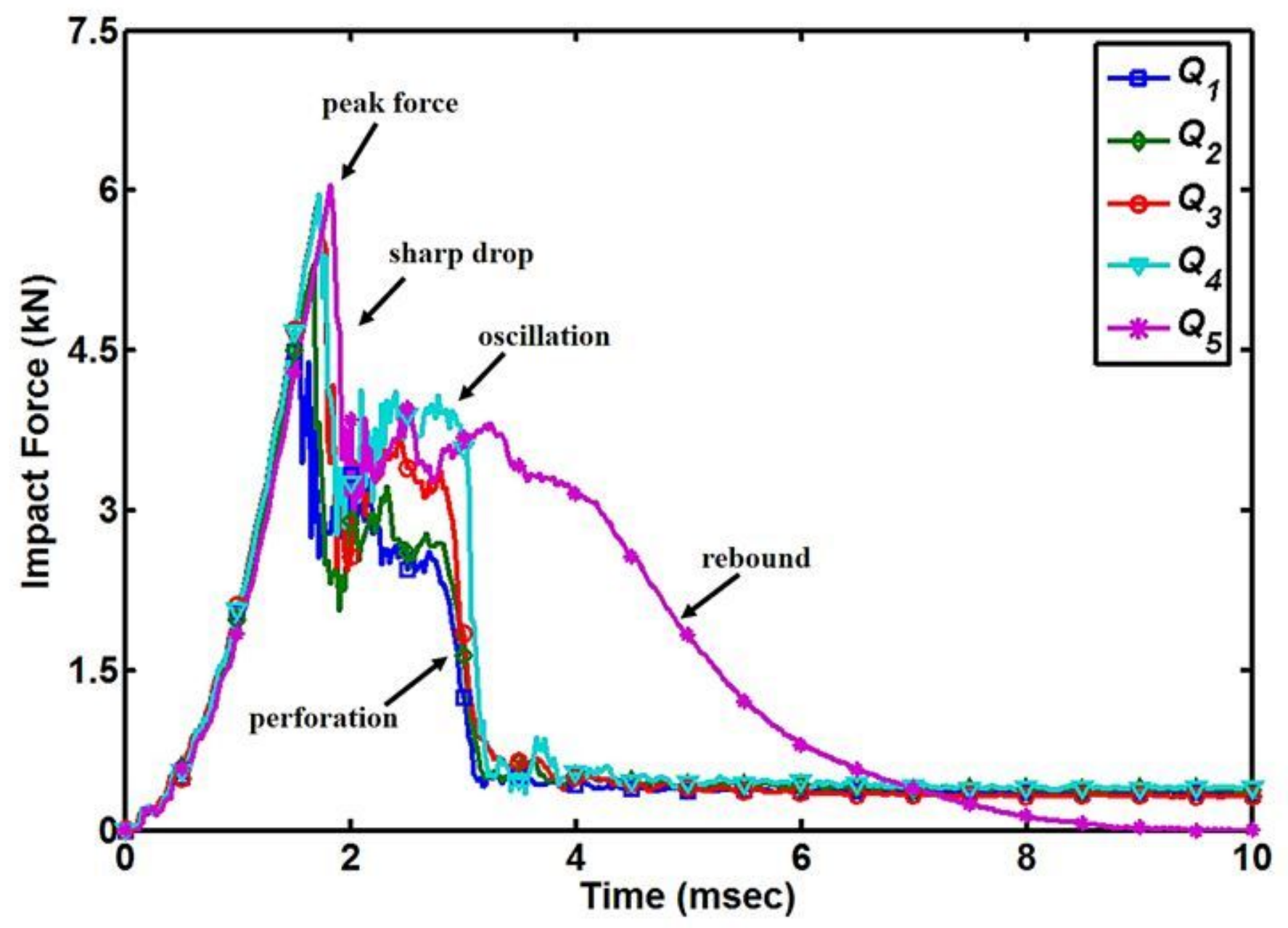

Figure 3

Impact force versus time diagram for all quasi-isotropic composite plates 


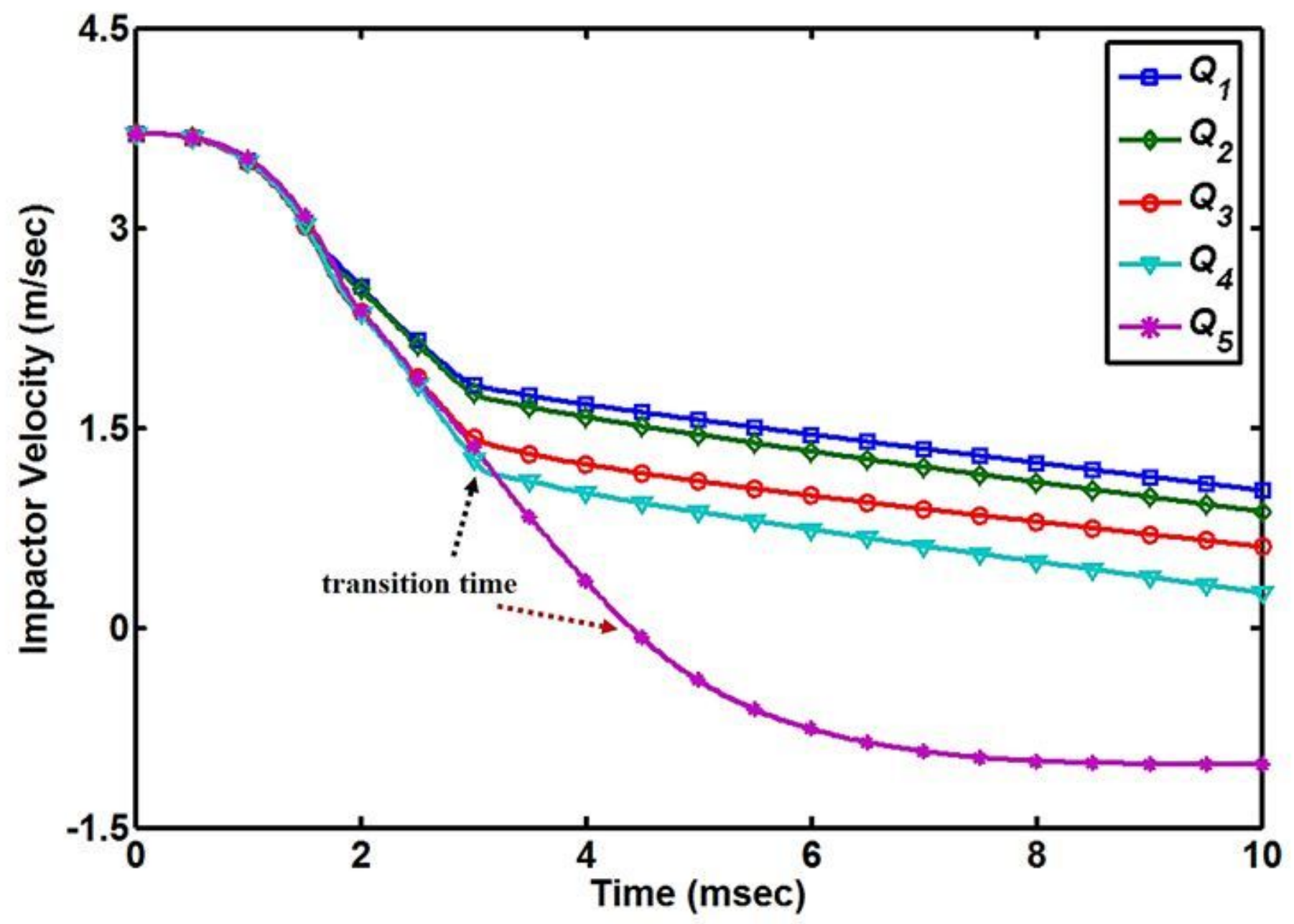

Figure 4

Impactor velocity versus time diagram for all quasi-isotropic composite plates. 


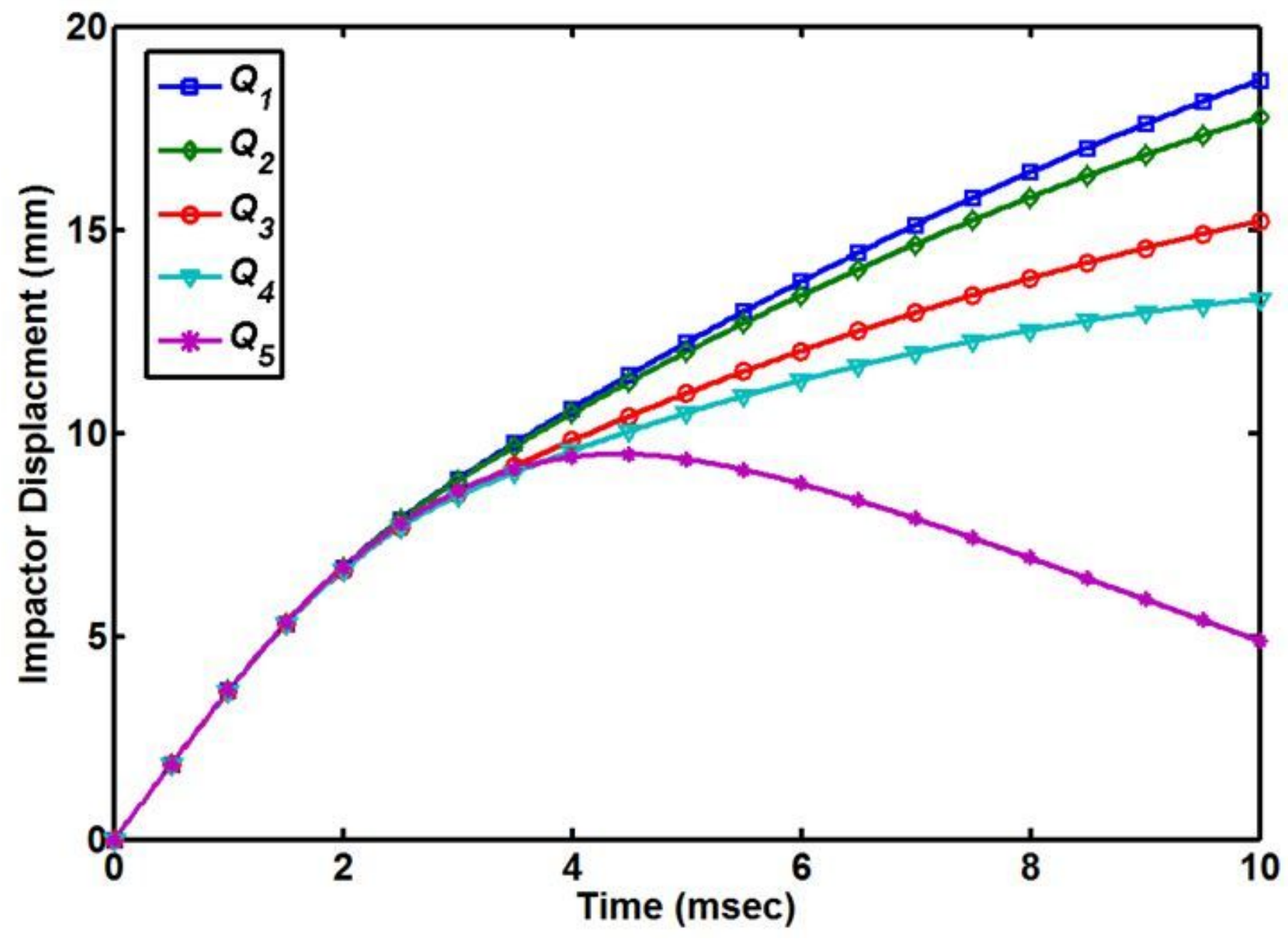

Figure 5

Impactor displacement versus time diagram for all quasi-isotropic composite plates 


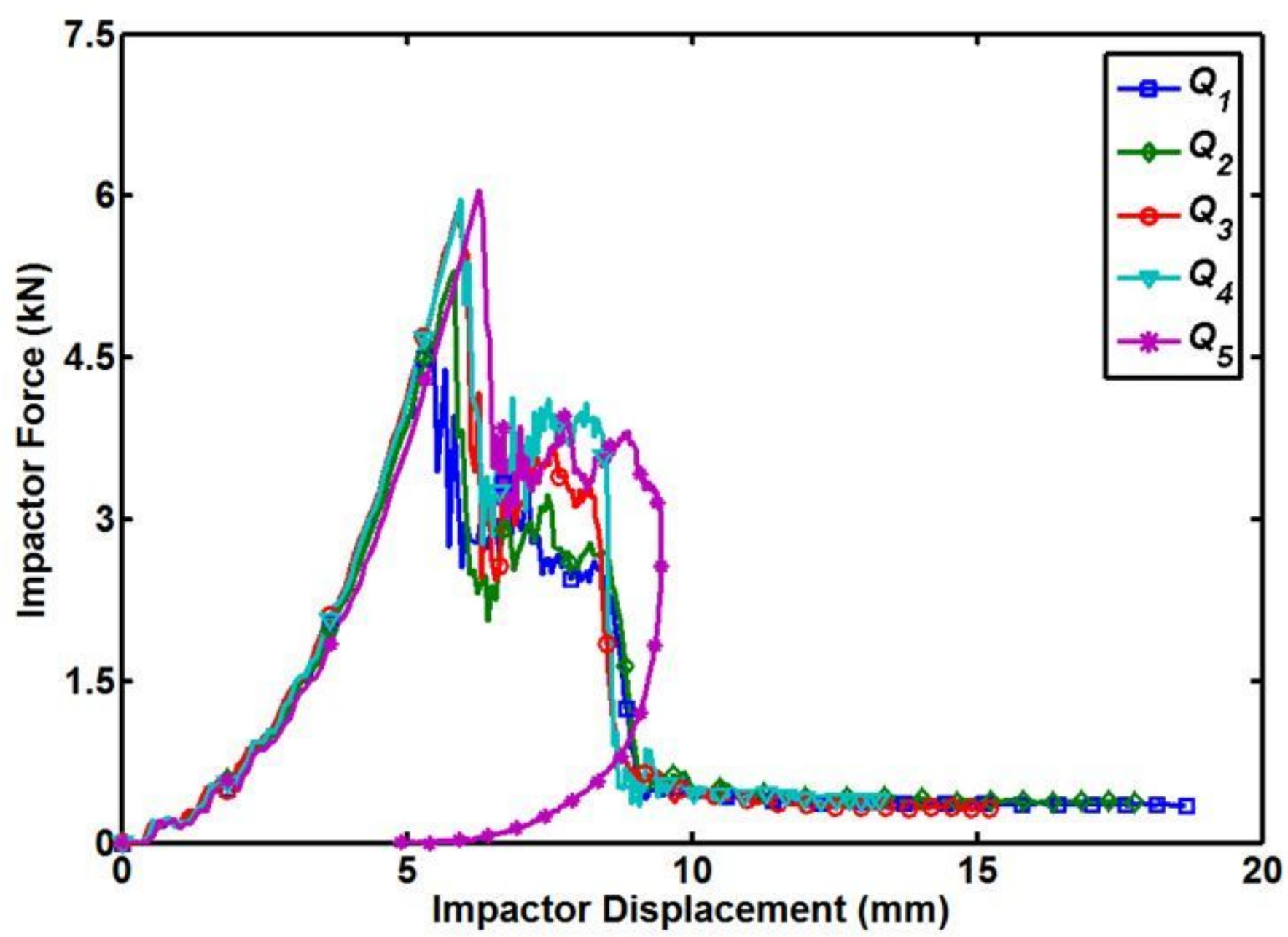

Figure 6

Impact force versus displacement diagram for all quasi-isotropic composite plates 


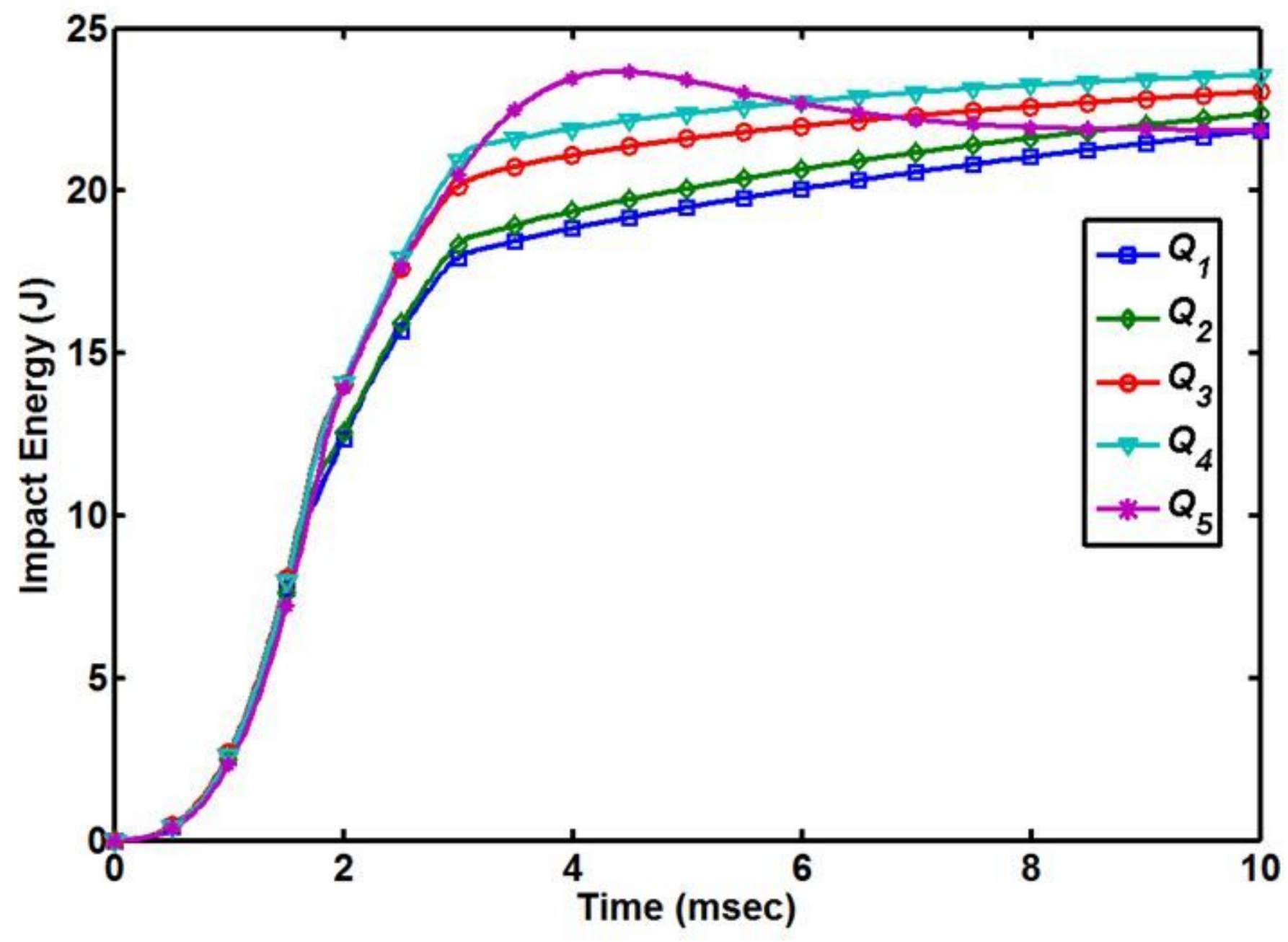

Figure 7

Absorbed energy versus time diagram for all quasi-isotropic composite plates. 


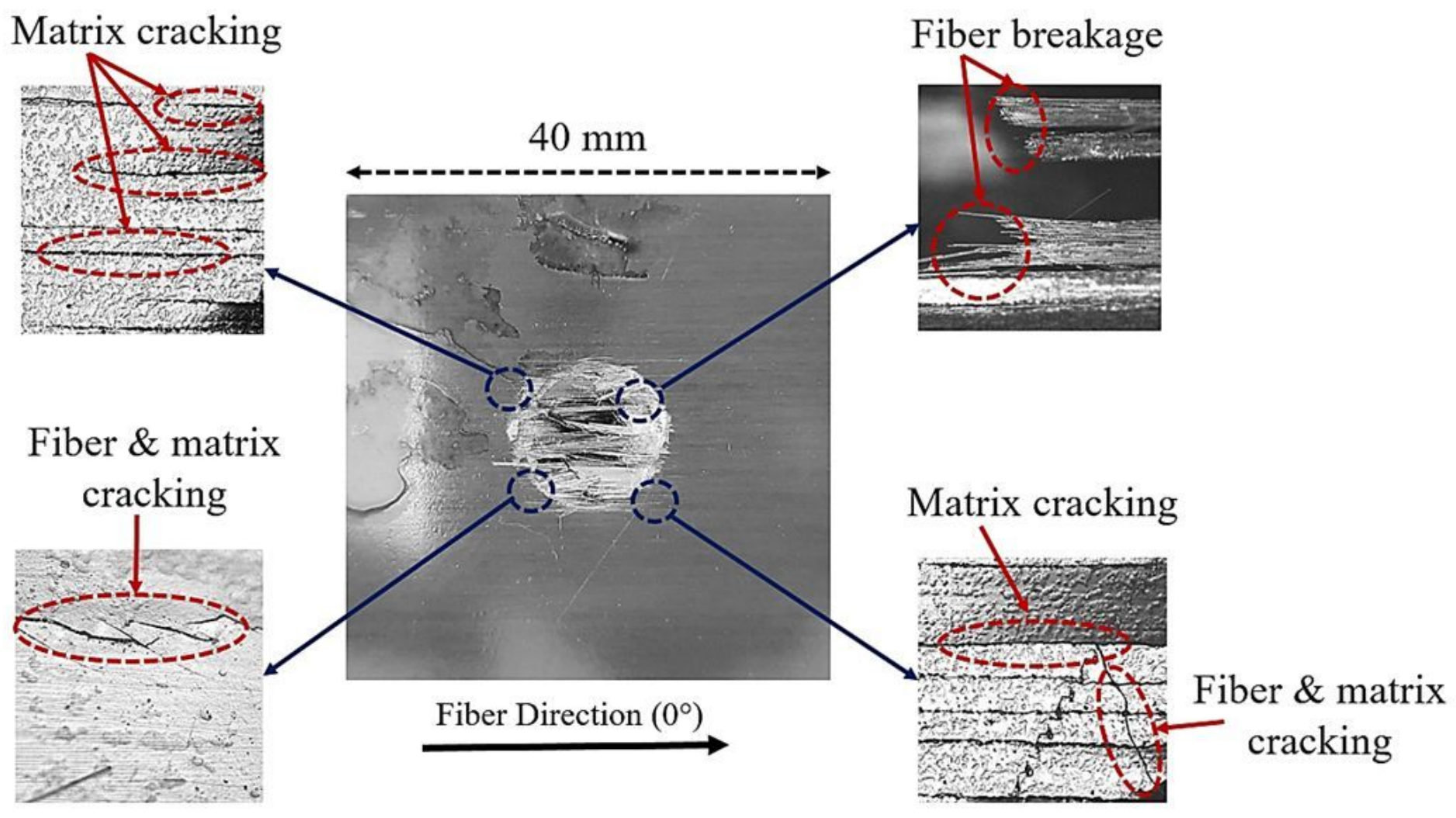

Figure 8

Damages on the top face of fully dry composite plate (Q1). 


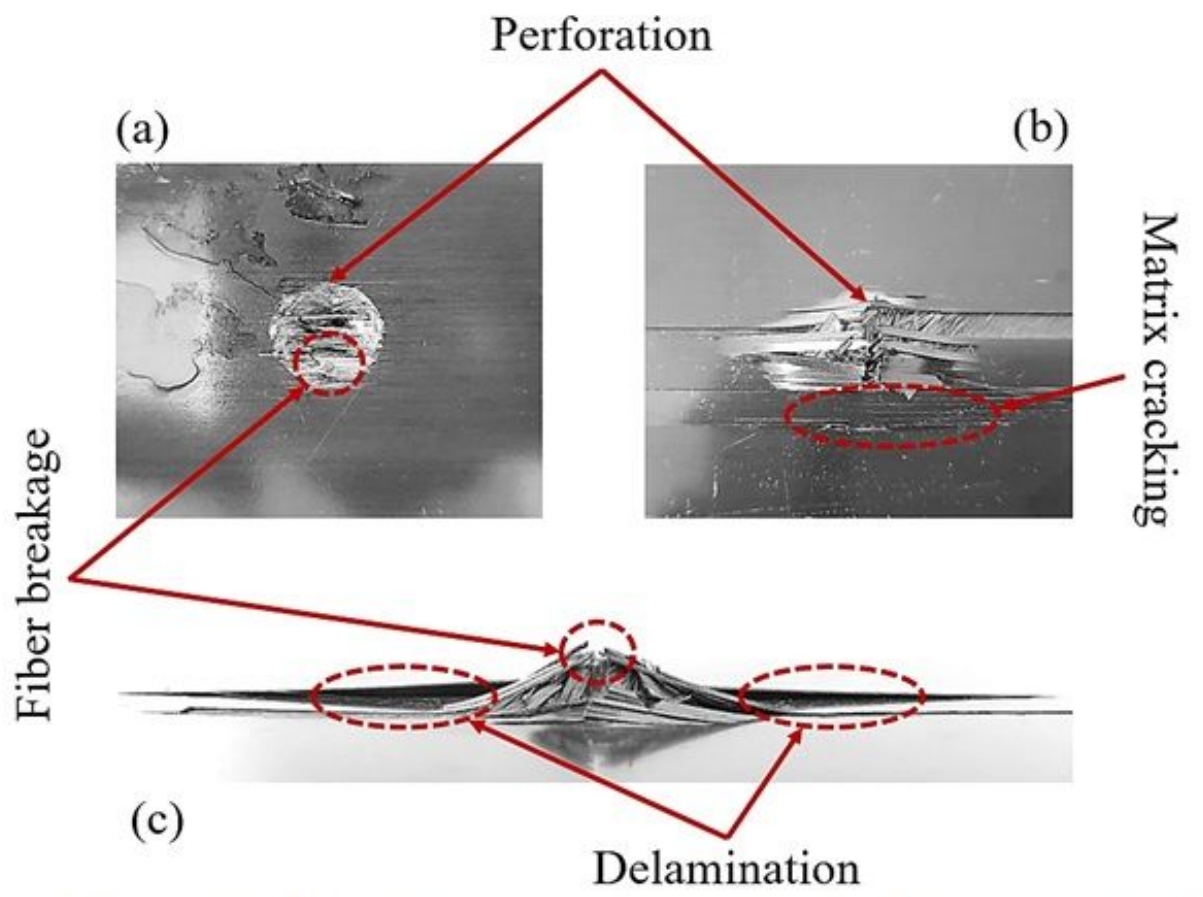

i) Damages in the fully dry $\left(Q_{1}\right)$ composite plate (a) top view, (b) bottom view and (c) side view.

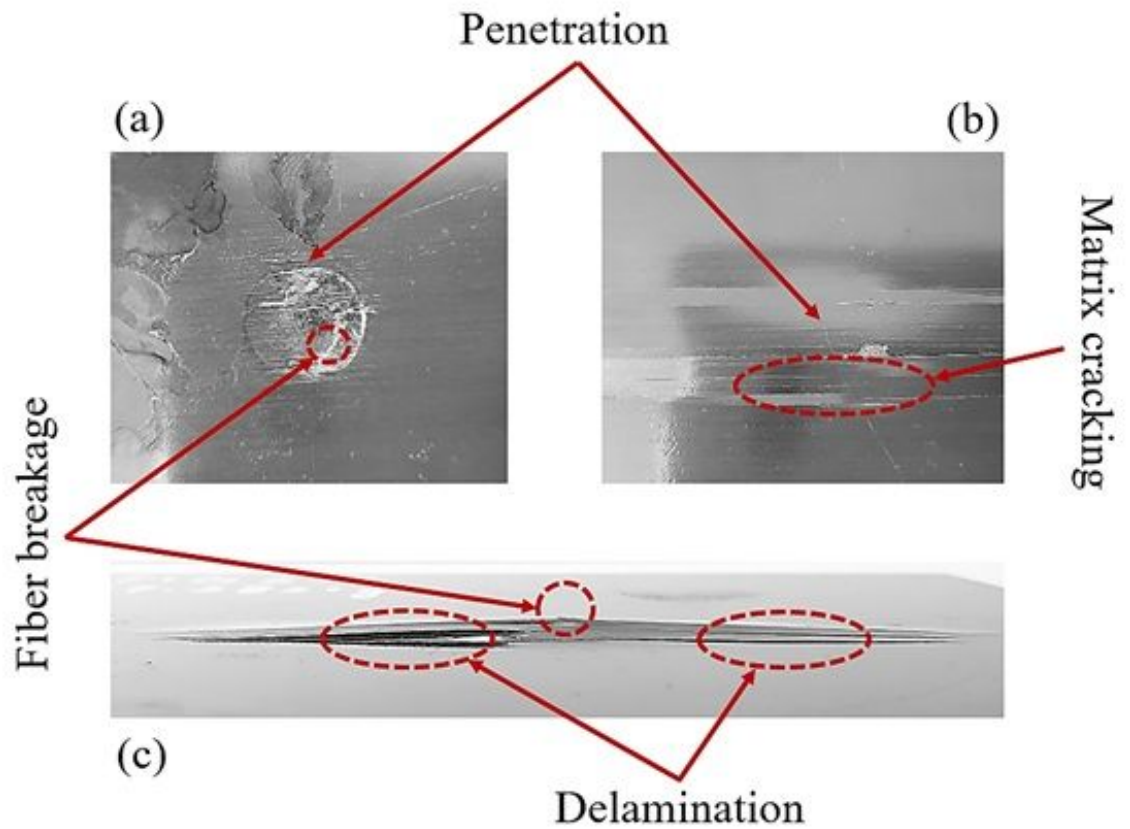

ii) Damages in the fully saturated $\left(Q_{5}\right)$ composite plate (a) top view, (b) bottom view and (c) side view

\section{Figure 9}

Different views of damages in i) fully dry (Q1) and ii) fully saturated (Q5) composite plates 


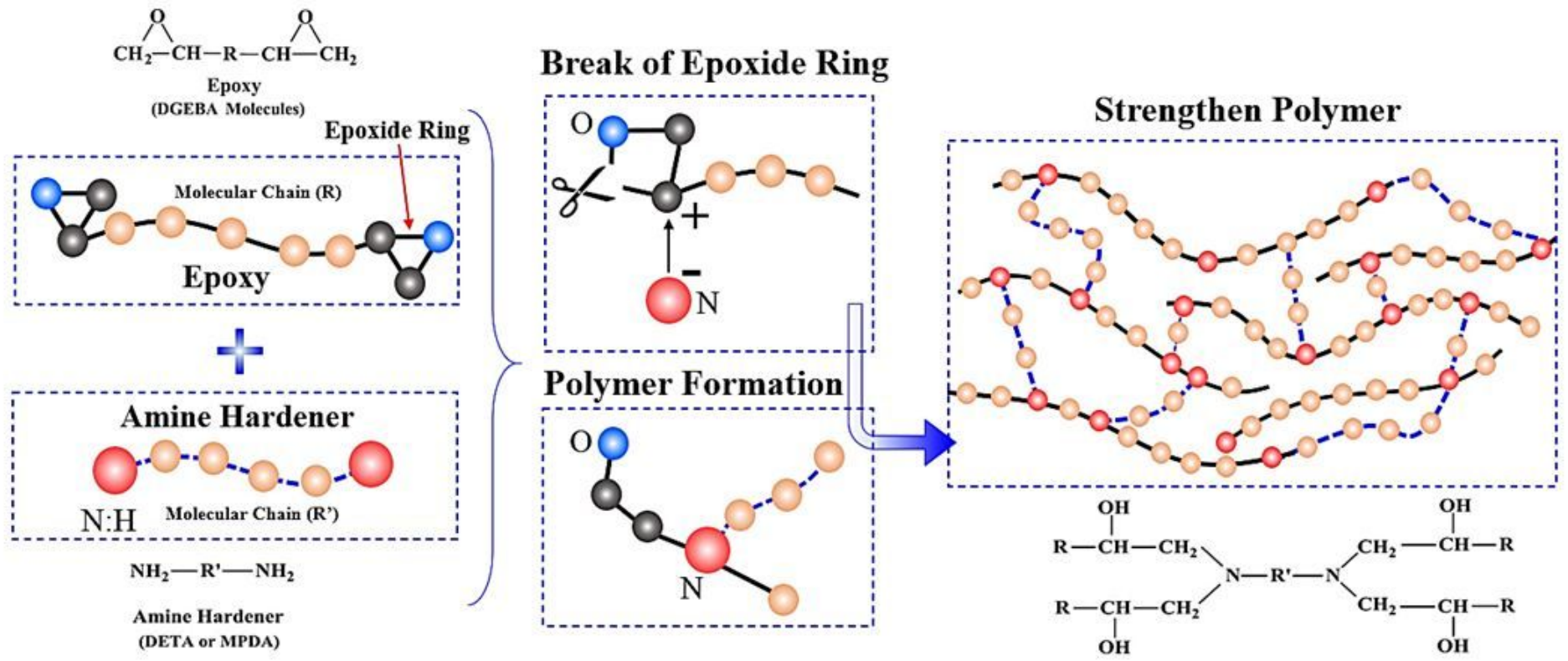

Figure 10

Schematic representation of reactants and formation of crosslinks in epoxy resin 
(a)

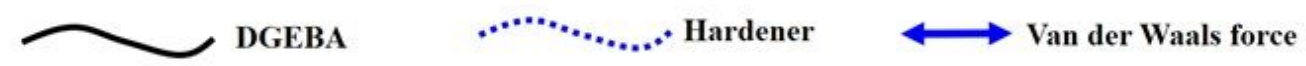

$\leftrightarrow+$ Induction force or orientation force A-H:B Hydrogen bonding

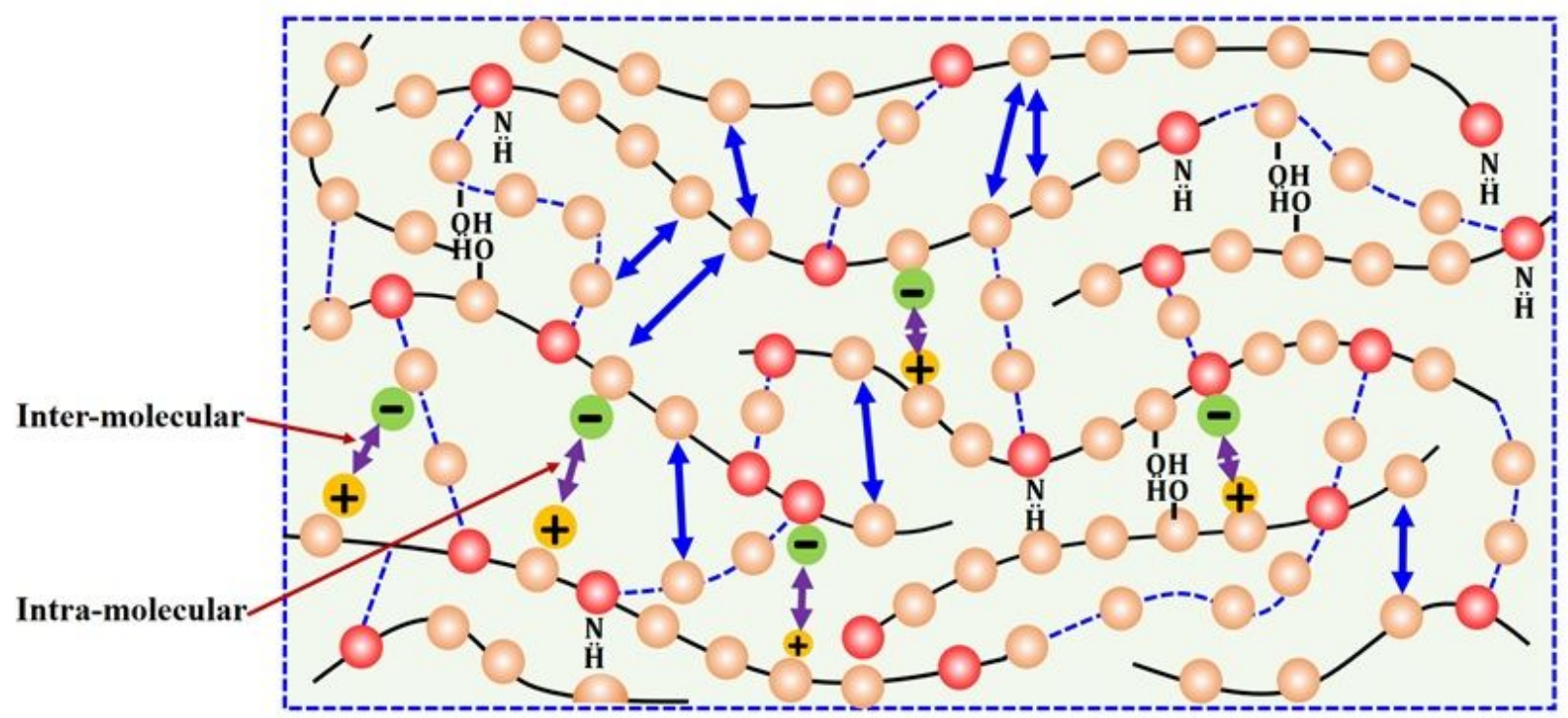

(b)

${ }^{\mathrm{H}} \mathrm{O}^{\mathrm{H}}$ Water molecule (polar) ${ }^{\mathrm{C}} \mathrm{O}^{\mathrm{H}}$ Water molecule $\quad \forall \ldots \rightarrow$ Weakened Van der Waals force

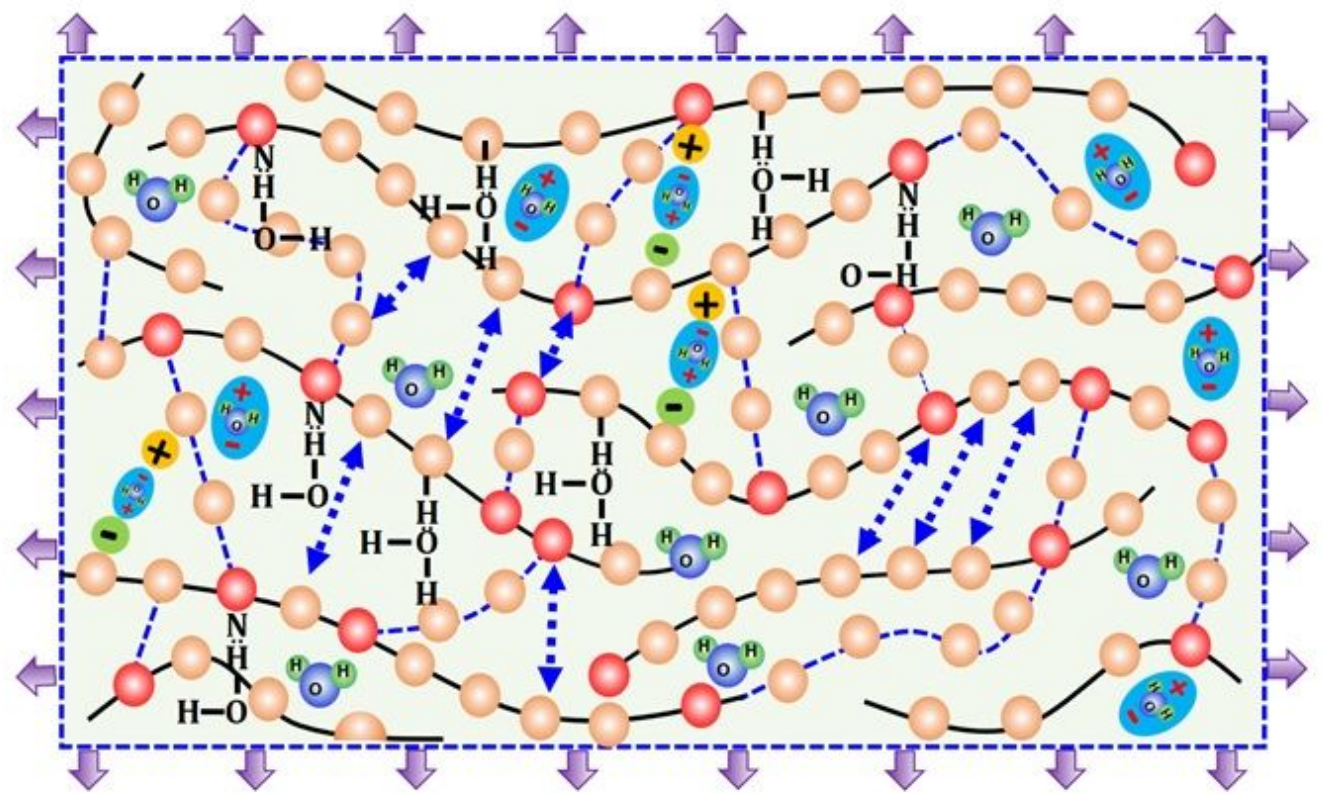

Figure 11

Schematic diagram of the (a) Van der Waals force, induction force or orientation force, and hydrogen bonding of epoxy molecules before absorbing the moisture content and (b) interaction between the moisture content and epoxy, weakened Van der Waals force, and disruption of hydrogen bonding of epoxy molecules after absorbing moisture. 


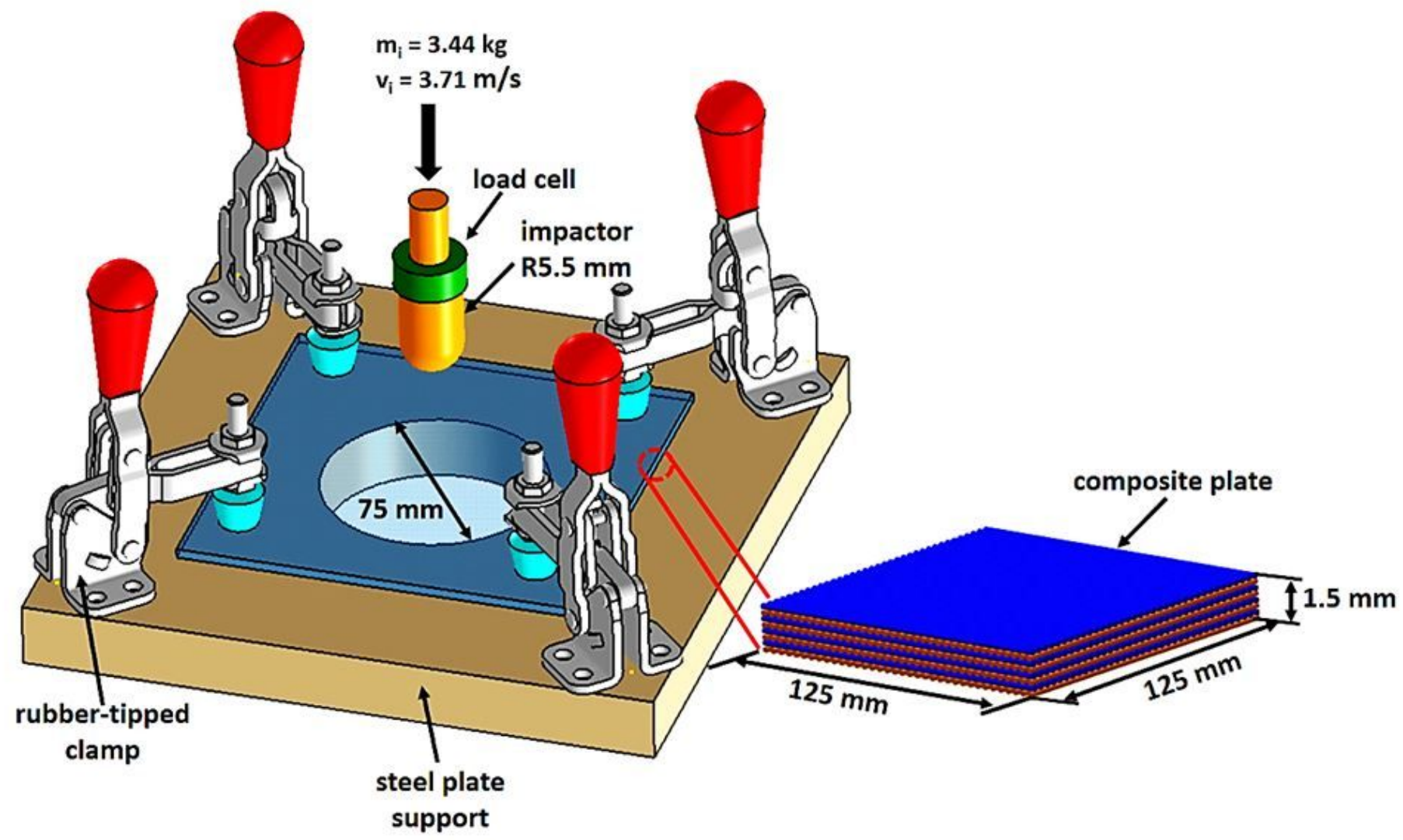

Figure 12

Schematic diagram low-velocity impact test for quasi-isotropic composite plates. 